\title{
Trapped in a Vicious Cycle of Violence: A Qualitative Inquiry into the Experiences of HIV Serodiscordant Married Couples
}

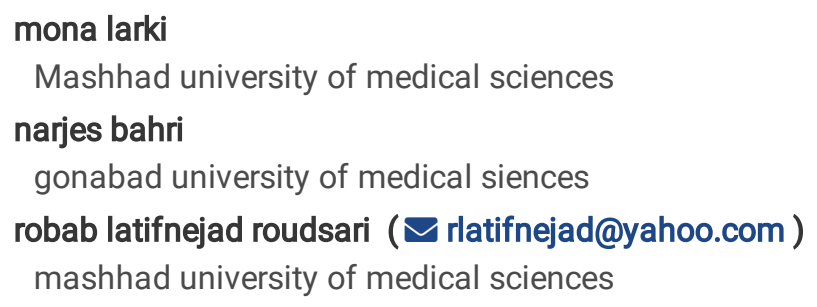

\section{Research}

Keywords: HIV, AIDS, HIV Serodiscordant, Violence, Gender-based Violence

Posted Date: December 18th, 2020

DOl: https://doi.org/10.21203/rs.3.rs-130224/v1

License: @ (i) This work is licensed under a Creative Commons Attribution 4.0 International License. Read Full License 


\section{Abstract}

Background: Violence against women is a major, complex, multidimensional and widespread public health concern worldwide. The current qualitative study was conducted to understand the experience of violence among HIV negative women in serodiscordant relationships.

Methods: A qualitative description (QD) was conducted from October 2018 to January 2020 (16-month period) in Mashhad, Iran. The researchers recruited 15 HIV negative women who lived with HIV positive men through purposive sampling method. The data were collected using semi-structured interviews. Data analyzed using conventional content analysis adopted by Graneheim and Lundman (2004).

Results: The main overarching theme emerged entitled: trapped in a vicious cycle of violence. It consisted of four categories of selfdirected violence, intimate partner violence, cultural violence and structural violence. The cycle of violence began soon after awareness of husband's infection with acts such as suicide attempts and a sense of abhorrence for living with an infected person, and continued with confrontation with various types of violence in the family and society.

Conclusions: This study provided an insight into different aspects of violence in Iranian women in HIV serodiscordant relationships. Healthcare providers should be able to address topics related to the violence for women who are in HIV serodiscordant relationships.

\section{Background}

The Joint United Nations Program on HIV/AIDS 2019 (UNAIDS) announced that, more than 37.9 million individuals currently live with HIV worldwide(1). It is the second most common cause of mortality among communicable diseases(2), and will become the first cause of death by 2020(3). Violence and the fear of violence have been identified as an important key factor for vulnerability to HIV infection for women of different countries(4). Violence against women is a critical, complex, multidimensional and widespread public health concern(5). This phenomenon embedded in cultural, social and family patterns(5). Recent statistics by the World Health Organization showed that one in every three women is vulnerable to physical and sexual violence and UN (United Nations) added that only $40 \%$ cases of violence seek for any sort of help(6).

One of the key populations for prevention of HIV are serodiscordant couples(7). HIV serodiscordant relationship refers to a mixedstatus and situation, where one of the partners is HIV positive, while the other is HIV negative(8). Among people with HIV who are in stable relationships, up to $50 \%$ are in serodiscordant relationships (9). HIV serodiscordance relationships, increase the odds of HIV negative partner being infected by HIV by $8-26 \%$ yearly compared to the other couples(10). When partners make aware of their HIV status together in serodiscordant relationships often face major challenges including gender-based violence, lack of sexual desire, divorce and abandonment, self-blaming, the stress of possible transmission, financial pressures, HIV-related stigma, family breakdown, desertion and isolation; all of which may have a negative influence on their relationships (11-15). A study conducted on serodiscordant couples, indicated that exposure to intimacy violence partner differed significantly between men (28.6\%) and women (89.3\%)(16). Mashaphu (2018) argued that there is a high level of intimacy violence partner in HIV serodiscordant couples, therefore, intervention programs should address gender-based violence and inequity among heterosexual couples(16). Patel (2016) suggested that counseling programs in relation to intimate partner violence may be important in preventing the risk of HIV transmission to HIVnegative wives(17).

The issue of violence, which is occurred within a social context could be influenced by gender norms, interpersonal communications and sexual stereotypes. Many have debated that women's experiences of violence could not be examined with traditional quantitative approaches, regardless of its context $(18,19)$. Qualitative research methods have enhanced in-depth insight into the subjective experience of violence and provide a better understanding of the manifest and latent meanings embedded within the context(20). Besides, qualitative research is a very useful and rigorous approach for investigating sensitive topics such as HIV and violence(21). It seems that conducting research about women's experiences of violence is essential for the reason of identification, prevention, control and elimination of violence and also to provide required support services for female victims of violence (22). Several qualitative studies conducted on women's experiences are more focused on intimate partner violence and another person as being the cause of violence against women have not been considered $(16,22,23)$. Additionally, more studies which have been conducted in this context in Iran have focused on HIV positive women and there is no evidence to explain the experiences of violence in Iranian HIV-negative 
women with HIV-positive husband i.e., HIV serodiscordant couples. Hence, the current qualitative study was designed and performed with the purpose of understanding the experience of violence among HIV negative women in serodiscordant relationships.

\section{Material And Methods Design}

We used a qualitative description (QD) study. This method attempts to describe the issue literally but attempts to explain the findings not moving too far from that literal description(24).

\section{Participants}

For the purpose of this study, the Clinic of Behavioral Disease Counseling was chosen as the study setting. The reasons for the selection of this clinic were that it was located in the central part of Mashhad, Iran and all patients with HIV and their wives referred to it to receive their health and counseling services and their medical records were available too. The study was conducted from October 2018 to January 2020 (16-month period). The participants were 15 HIV-negative married women who lived with HIV-positive men. The inclusion criteria for the study were women with serdiscordance relationship, the ability to talk and express emotions and feelings, and the desire to participate in the study. Participant with unwillingness to continue the interview were excluded from the study.

\section{Sampling}

The purposive sampling method was used to draw the sample for the study. To recruit participants, one of the health care providers in the clinic contacted the eligible members by phone call and explained the research objectives to them. Then, a convenient time was set for interviews with the individuals, who agreed to take part in the study.

\section{Interview Procedures:}

The method used to data collection was semi-structured interviews. The interviews were semi structured and carried out individually and face to face. All interviews were conducted in a room at the Clinic of Behavioral Disease Counseling. Due to the sensitivity of the phenomenon under investigation and in order to achieve a greater insight into the experiences of the participants, all interviews were conducted by the first researcher, who is a reproductive health researcher with previous experience of interviewing females with highrisk sexual behavior in prison. The interviews started with an open-ended and general question: Tell me more about the relationship with your husband? Then continued with main questions: what experiences do you have of being victim of violence? Probing questions were also used during the interviews: can you give me an example? Could you please explain more about that? Also, during interview process, researcher considered non-verbal cues such as body language. The interview continued until saturation was achieved and no further concepts were detectable in the participants' experiences. One interview was conducted with each participant. The length of Interviews was between 50-70 minutes.

\section{Ethical aspects}

All participants in this research volunteered to take part in the study after being explained to the objectives, the benefits, confidentiality and anonymity of information they were going to give. All participants were given an informed consent form, which they read and signed. Notwithstanding to verbal consent, written consent obtained from the participants. Also, it was emphasized to all women that they can withdraw from the study at any time. If the participants were not comfortable to answer any question, then they were not forced to give response. Considering that the issue under investigation was very sensitive to achieve a great insight, all interviews were conducted by one researcher (ML). The researcher gave an opportunity to participants to ask any questions about subject under study after the interview completion. Before the end of the interview, each participant was asked for agreement to be contacted again in the future if necessary, in relation to this study. All the participants agreed for it and gave their phone number to the researcher. At the end of the interview, a gift was given to the participants for compensation. All the information collected from participants was kept confidential and instead of using their names, they were given unique numbers to be used in analysis. Ethical approval for the current 
study was obtained from ethical committee of Mashhad University of Medical Science (Code of Ethics.

IR.MUMS.NURSE.REC.1397.022).

\section{Data analysis}

All interviews were audio-recorded, transcribed verbatim and entered into MAXQD version 12 that was developed and distributed by VERBI Software based in Berlin, Germany. Data analysis began immediately after the first interview. We used the Graneheim and Lundman's method (2004) to analyze the data(25). At first the text of the interviews was read several times to obtain a general understanding and sense of the whole of their content. Then the text of each interview was divided into meaningful units as words, phrases, sentences, and paragraphs. Thereafter the meaning units were condensed and labeled with code. Then the meaning of codes was compared in terms of similarities and differences, and the related codes with similar meaning were put in the initial categories. Finally, with the advancement of data analysis, the initial categories or subcategories were developed and categories formed, from which an overarching theme was emerged.

\section{Trustworthiness}

In this study, credibility was established through interviews and including appropriate number of participants using maximum variation strategy. Also, the field notes, which contained the researcher's thoughts and feelings, impressions, as well as the interpretation of interviewees' non-verbal cues and body language enhanced credibility. For dependability, the researcher gave data to an independent coder who was skilled in the field of qualitative research to do an independent examination of the data and confirm them. To ensure confirmability supervisor review of findings, interpretations, and conclusions of the study greatly increased the confirmability of this study; so, conducting an audit trial was possible. For transferability, clear and thick description of culture, context, the method of participant selection, and characteristics of participants as well as the process of the data analysis was provided.

\section{Results}

\section{Participant characteristics}

The participants were 15 married women. The ages of the respondents ranged from 30 to 60 . Five female's husbands (33.3\%), who were interviewed in this study were HIV positive and HCV positive, whilst $10(66.6 \%)$ were HIV positive only. Exception of one couple, all couples had children. Four of the couples $(26.6 \%)$ had one child, while two couples had four. The age of the females' children ranged from under seven to over thirty-four. The majority of the females were in their childbearing age, when they discovered their status. Most of the females completed lower secondary school education and three females had a diploma. The majority of the females chose not to disclose their status to their children. Only one member informed her children and one member informed her entire family. The characteristics of participants are presented in Table 1. 
Table 1

The profile of participants $(n=15)$

\begin{tabular}{|c|c|c|c|c|c|c|c|}
\hline Participant & $\begin{array}{l}\text { Age } \\
\text { (Years) }\end{array}$ & $\begin{array}{l}\text { Duration of } \\
\text { marriage } \\
\text { (years) }\end{array}$ & Education & Employment & $\begin{array}{l}\text { Husband's } \\
\text { occupation }\end{array}$ & Children(n) & $\begin{array}{l}\text { Economic } \\
\text { status }\end{array}$ \\
\hline 1 & 36 & 18 & $\begin{array}{l}7 \text { years of } \\
\text { schooling }\end{array}$ & Housewife & $\begin{array}{l}\text { Temporary } \\
\text { employees }\end{array}$ & 2 & Poor \\
\hline 2 & 38 & 5 & $\begin{array}{l}\text { High school } \\
\text { diploma }\end{array}$ & worker & employed & - & $\begin{array}{l}\text { Fairly } \\
\text { appropriate }\end{array}$ \\
\hline 3 & 34 & 8 & $\begin{array}{l}9 \text { years of } \\
\text { schooling }\end{array}$ & seller & $\begin{array}{l}\text { Temporary } \\
\text { employees }\end{array}$ & 1 & Poor \\
\hline 4 & 45 & 30 & $\begin{array}{l}5 \text { years of } \\
\text { schooling }\end{array}$ & tailor & unemployed & 3 & $\begin{array}{l}\text { Fairly } \\
\text { appropriate }\end{array}$ \\
\hline 5 & 30 & 15 & $\begin{array}{l}5 \text { years of } \\
\text { schooling }\end{array}$ & Housewife & $\begin{array}{l}\text { owned private } \\
\text { businesses }\end{array}$ & 1 & $\begin{array}{l}\text { Fairly } \\
\text { appropriate }\end{array}$ \\
\hline 6 & 34 & 12 & $\begin{array}{l}9 \text { years of } \\
\text { schooling }\end{array}$ & Housewife & $\begin{array}{l}\text { Temporary } \\
\text { employees }\end{array}$ & 1 & Poor \\
\hline 7 & 37 & 13 & $\begin{array}{l}4 \text { years of } \\
\text { schooling }\end{array}$ & Housewife & $\begin{array}{l}\text { Temporary } \\
\text { employees }\end{array}$ & 2 & Poor \\
\hline 8 & 39 & 10 & $\begin{array}{l}8 \text { years of } \\
\text { schooling }\end{array}$ & Housewife & $\begin{array}{l}\text { Temporary } \\
\text { employees }\end{array}$ & 1 & Poor \\
\hline 9 & 35 & 14 & $\begin{array}{l}6 \text { years of } \\
\text { schooling }\end{array}$ & Housewife & $\begin{array}{l}\text { Temporary } \\
\text { employees }\end{array}$ & 2 & Poor \\
\hline 10 & 41 & 20 & $\begin{array}{l}7 \text { years of } \\
\text { schooling }\end{array}$ & Housewife & $\begin{array}{l}\text { Temporary } \\
\text { employees }\end{array}$ & 3 & Poor \\
\hline 11 & 40 & 19 & $\begin{array}{l}8 \text { years of } \\
\text { schooling }\end{array}$ & Housewife & $\begin{array}{l}\text { Temporary } \\
\text { employees }\end{array}$ & 4 & Poor \\
\hline 12 & 36 & 14 & $\begin{array}{l}6 \text { years of } \\
\text { schooling }\end{array}$ & worker & $\begin{array}{l}\text { owned private } \\
\text { businesses }\end{array}$ & 2 & $\begin{array}{l}\text { Fairly } \\
\text { appropriate }\end{array}$ \\
\hline 13 & 35 & 7 & $\begin{array}{l}\text { High school } \\
\text { diploma }\end{array}$ & Housewife & unemployed & 4 & poor \\
\hline 14 & 42 & 21 & $\begin{array}{l}8 \text { years of } \\
\text { schooling }\end{array}$ & Housewife & unemployed & 2 & poor \\
\hline 15 & 60 & 35 & $\begin{array}{l}\text { High school } \\
\text { diploma }\end{array}$ & Housewife & $\begin{array}{l}\text { owned private } \\
\text { businesses }\end{array}$ & 2 & good \\
\hline
\end{tabular}

The results of the analysis included 96 meaning units, 12 subcategories, four categories and one theme. The main overarching theme emerged entitled: trapped in a vicious cycle of violence. It consisted of four categories of self-directed violence, intimate partner violence, cultural violence and structural violence (Table 2). 
Table 2

Theme, categories and subcategories extracted from the study

\begin{tabular}{|lll|}
\hline Subcategories & Categories & Theme \\
\hline Suicidal ideation & Self-directed violence & Trapped in a vicious Cycle of Violence \\
\hline Self-Injurious behavior & \\
\hline Self-hate & \\
\hline Verbal harassment & \\
\hline Psychological aggression & \\
\hline Physical harm & Cultural violence partner violence \\
\hline Sexual assault & \\
\hline Social marginalization & \\
\hline Stereotypes and cultural norms & \\
\hline Deprivation of the right to economic participation & Structural violence \\
\hline The lack of legal protection & \\
\hline Health disparities & \\
\hline
\end{tabular}

\section{Main theme: Trapped in a vicious cycle of violence}

Violence often occurs in a repeated cycle. The cycle of violence began soon after the awareness of husband's infection and was started with acts such as suicide attempts and a sense of abhorrence for living with an infected person, and continued with confrontation with various types of violence in the family and society.

\section{Category 1: Self-directed violence:}

A topic raised by study participants was self-directed violence. Women sometimes experienced self-injuries activities in the event of confronting with illness of husband or reactions of relatives.

1-1: Suicidal ideation: Some women reported that their husbands engaged in high-risk sexual behavior such as irregularly extra-marital relationships, which leads to their tendency to commit suicide. In this regard, one participant said: "When I was pregnant, I understood he betrayed me. I was suspicious of my husband's behaviors and I recently found a condom in his pocket. I was afraid that my surroundings do not accept me. Most of the times I think what should I do? Because of this, I tend to commit suicide for fear of getting AIDS" (P2. 38 Y).

1-2: Self-Injurious Behavior. Many participants spoke about doing self-injurious behavior. The participants mentioned their husband do not pay attention about their likes and dislikes and the decision in their life according to their wish. The husband's acts provoked the women to injure themselves. One female said that, "My husband is not concerned about living expenses, for instance, if I want to buy anything he never agrees with. He sells home appliances and doesn't pay any attention to the kids.

I take care of the children and always seek to give them comfort, but is it just my responsibility? In this condition, I do not want to eat and I like to have hit my head against wall" (P2. 38Y).

1-3: Self-hate: Women participating in the interview mentioned that they experienced restrictions imposed by their husbands. Indeed, they had no power to make any decision at home, without allowance of their husband. It led to their negative feelings about themselves. Only one participant stated that her activities are not limited by her husband: "I can't do anything without my husband's permission. I wish I could work outside and I could be financially independent. But my husband prevents me from working, he does'not financially support me at all. The dependency makes me more vulnerable to my husband's acts of violence ... I sometimes hate myself for not getting divorced" (Touching her face) (P11. 40 Y). 


\section{Category2: Intimate partner violence:}

Women in their serodiscordant relationships with a partner are usually victims of a combination of violence including verbal harassment, psychological aggression, sexual assault and physical harm.

2-1: Verbal harassment: Verbal violence, such as scurrility and screaming often has been experienced by women. Men consider verbal violence as a legal means to meet their needs and as a condition to protect his power over the family. Participants expressed we cannot talk and negotiate to each other in a constructive manner. One woman said

that: "When we speak to one another, he uses bad word. He begins to scream and cannot control himself at all. When he comes home, he stars constantly ordering me to do something with a high voice. He feels pride doing it" (P 2. 38Y).

2-2: Psychological aggression: It was reported by serodiscordant women that they are under psychological aggression which is a cause enduring damage to the sense of well-being of the women. The findings showed that almost the majority of the participants in the study mentioned psychological violence by their husband. In some cases, men tend to control their women. Trying to control and doing dominant behaviors by men were forms of psychological violence in women. One woman expressed that, "my husband is very suspicious. He constantly checks my mobile phone, even though my phone is always at home. He consistently says that women are worthless. When my husband says it, my confidence is going down" (P5. 30Y).

2-3: Sexual assault: A few of serodiscordant women talked about sexual assault. This type of violence affects free living opportunities and social status of women. They indicated having constant arguments and disputes towards sexual issues. One woman has mentioned forced unprotected sex with her husband: "I strongly believe condom continue to be used before a cure is found for HIV. But he doesn't want to use the condom. He said, I don't like using a condom. In this condition I cannot protect myself, because my husband doesn't put on a condom. I am forced to give him sex because I fear that he embarrasses my children" (P11. 40Y).

1-4: Physical harm: The effects of physical assault are usually more stated than other forms of violence. It is a way for the continuation and strengthening of the women's' obedience for men, where men do not achieve their goals through mental violence. The data showed that men use their physical strength or even cold weapons to threaten or cause physical pain to the women. One female stated: "he beat me up in front of kids. He used physical force such as hands and feet for choking and shoving me. I begged him to stop, but he said I like killing you and the kids" (P7. 37 Y).

\section{Category3: Cultural violence:}

Cultural beliefs could play an important role for HIV / AIDS patients and their families in adapting, coping with the disease and violence toward them and their families. Participants said that when relatives became informed that their spouse is HIV positive; they reject them from the family. Also, it was resulted in labeling and stigmatization in the community. Their relatives considered them distracting from the usual norms of society and prevented them from being accepted as a normal citizen in the community.

3-1: Social marginalization: Serodiscordant women chose not to disclose their status to their family and friends, as they found that women who disclosed their status were rejected by their relatives. The following quote explain this point: "My family' behavior has changed toward me. I am seronegative, but some people, who see me at the clinic with my HIV positive husband, they think that I am positive too. My family used to gather and eat together, but when they know that my husband is HIV positive, left their habit. In our society when people hear that such a woman has a HIV positive husband it is a very shameful condition. I think, this is an example of overt violence. I say to my husband that I am really suffering from this problem" (P 4. 45 Y).

3-2: Stereotypes and cultural norms: The patriarchal values and the unequal gender-based distribution of power in the family and neighbors, directly or indirectly, affect the violence against women. The women explained that due to the interference of people they have to face several problems. A participant specifically mentioned about her mother-in-law interference: "She believes in women's complete obedience to men and inherent aggression against them. My husband spends most of his time at her home and used to listen to his mother advice, who is not a right person for consultation. For example, she said to my husband you have power and you can transfer it (HIV) to your wife and you can infect her. My mother- in-low and I is always arguing together" (P 6.34 Y).

\section{Category4: Structural Violence:}


Structural violence, which reveals inequality in the distribution of jobs and resources among people living with HIV / AIDS, was one of the issues that serodiscordant women experienced due to living with HIV positive men. They confronted with deprivation from economic participation, the lack of legal protection and also health disparity.

4-1: Deprivation of the right to economic participation: Participants stated that their husbands lost their job and sources of income when their employer was informed of their status. One woman mentioned "my husband decided to disclose his status to the company, but they told her that they couldn't give her a job. He is unemployed. He afraid to go to other factories to look for a job, you know, because he feels that he will be approached the same. Several times I went to look for a job for him, but did not approached well. In this situation he's become more nervous with me and the kids"( $P$ 8. 39Y/O).

4-2: The lack of legal protection: From the interviews conducted with the women, it was found that the majority of the women still has not reported the violence to the legal organization. One woman mentioned, as they thought that they would not be supported by the legal system: "The law does not give sufficient protection for women in instances of violence. Men also know it. Once I went to court to divorce, but the judge did not pay any attention to me and said, you are a mother, you must endure" (P 12.36 Y).

4-3: Health disparities: The majority of participants in this study had strong relationships with their health care providers. They said that the Infection Disease Clinic plays a big role in providing support for us. But a few participants referred to the bad experiences from the healthcare providers in hospital. A woman who had a good relationship with her husband in this relation said: "When he (my husband) got sick, I strongly believed that, it is my responsibility to accompany her for going to the hospital without shame, but in the hospital where we went for care, one of the care providers loudly said that he is HIV positive. Also, the nurse gave care to my husband with a violent behavior, you know, and when I protested him, he, with a bad tone, said, your husband is HIV positive and I should take care of myself. In this situation, I just cried and came out of the room. I felt so bad" (Lip biting) (P 13. 35 Y).

\section{Discussion}

The key findings that emerged from the study indicated the experience of various types of violence among HIV serodiscordant women. The vicious cycle of violence, rooted in misconceptions about AIDS, began soon after the awareness of husband's infection and was started with acts of suicide attempts and a sense of hatred for living with an infected person, and continued with confrontation with various types of violence in the family, and society. HIV is a phenomenon in serodiscordant relationships that involves both partners. It is associated with unique stressors. In a study a high rate (83.1\%) of suicidal attempt was reported in HIVpositive people(26). It is also, a stressful event in women's life that led to self-directed violence. In this study the major problem in females was psychological reactions in dealing with the issue of difference in serostatus. They bear the psychological pressure from their husband and the society, which often led to psychosocial problems as self-hate. Although in these cases violence often occurs by an intimate partner but it takes in different forms such as violence by a family member or relatives (27). Part of the experience of violence is related to interacting with the husband. We categorized intimate partner violence to verbal, sexual, psychological and physical. In general, women in their relationships with a partner are usually victims of a combination of violence. So, it seems difficult to separate the different dimensions of violence(28). In this study women explained that they had low power and authority for decision making in their life issues. Psychological and verbal violence included behaviors that intended to undermine women's confidence and self-esteem. Some of the verbal violence included the use of words such as foolish, fat and silly (29).

Psychological violence can be subtle and there is no clear definition for it (30). In fact, it may be more effective than physical violence on women's emotional status. Also, UNESCO states that psychological abuse has not been given proper attention(31). Sexual violence was presented by fewer women, since, it seems that women were faced with a standard for allegorical. They attribute this phenomenon to the self-esteem of the spouse and to the submissive and obedient and quiet role of women. This type of violence would affect living opportunities and social status of women. Also, fewer statements were attributed towomen's self-censorship and shame in this study. Managing emotional and sexual intimacy can be challenging in HIV serodiscordant relationships because of concerns about HIV transmission, the burden of initiating and maintaining safer sex, and the health status of the affected partner(32). This study showed that serodiscordant couples have numerous challenges about sexual relationship. Serodiscordant women indicated that there is a lack of regular condom use in some men in sexual relationships. Men consider having sex without any protection as a right for themselves. In this condition, men face women's objection, and this itself leads to sexual and psychological violence against women. This finding is congruent with the results of a study conducted in Uganda in which women's fear of HIV transmission and frequent demand for using condom by the male partner played an important role in the sexual violence(33). One 
study reported that HIV-infected men deliberately infect their partners with HIV infection(34). McDonald et al. (1996) declared that condom in serodiscordant relationships is as a reminder of serodiscordance, which would reduce the motivation for use(35). This issue can adversely affect women's sexual desire and may lead to increased psychosexual problems that often escalate violence(36). For HIV uninfected women, who are in an abusive relationship with coercive sexual intercourse, there is a reduced ability to negotiate for safe sex and as a consequence their chance for getting HIV is increased(37). A study by Smith and colleagues describes women's experiences of physical, emotional and verbal violence. Women were burned with cigarettes, thrown to the wall and were attacked in different ways. Some of them experienced emotional intimidations along with physical threats with a weapon. Their partners insulted them verball. Besides, they controlled women and violated their right of freedom, including having the right of financial independence(38). The results of another study showed sexual violence in the form of coercion in sex, intercourse with the purpose of causing pain and verbal acts of humiliation(23).

Part of the experience of violence is related to interactions in society. It is a type of violence that is not visible but its effects can be felt. In general, women in our study not only lacked social support, but were also subjected to violence by relatives. Social exclusion was occurred following disclosing of HIV by families and community.; although, the structure,

source and consistency of social support networks, play a significant and successful role in helping women with abusive partners(39). The findings in our study about social marginalization are supported by other studies. In HIV serodiscordant relationships, the HIVnegative partner also confronts stigma and social challenges(40), because HIV/AIDS is a family disease, and when one member of the family has HIV/AIDS, its impact can be felt throughout the entire family (41). So, couples often tend to hide the disease from community members in order to protect themselves from stigma and violence. Rispel et al. (2015) in a qualitative study on serodiscordant couples concluded that the experiences of the stigma were common in these couples, including, expressing rumors and labeling an HIV-negative person as HIV- positive one(42). In some traditional societies, there is a negative attitude towards women's roles and rights. Traditional beliefs that men have a right to control women and its acceptance by women has made women and girls vulnerable to violence and led to greater gender discrimination in the communities (43). The exploitation of female and the right of husbands to threaten their wives physically is rooted in a long patriarchal tradition: the tradition that men are the head of their homes and those women are to obey them(44). One study in Kolkata found that with the severity of the disease, a large number of patients loss their jobs, confronted with reduced family income and increased expenditure for care seeking, and face greater economic outcomes, reflected by selling assets(45). Although all women have experienced violence in this study, but only one of the women reported it to the law enforcement authority. This is consistent with the findings of other studies and leads to non-authority figures of violence $(33,46)$. In this study, women were neglected when they came to law enforcement agencies. Women considered this situation as violence against themselves. In one study it was reported that half of the participants in their sample of abused women were dissatisfied with the police response to their assailants(47). It should be considered that violence is a social issue and requires attention in criminal justice systems(48).

WHO notes the establishment of international and national legal structures promoting gender equality and strengthening police and other criminal justice agencies' responses to violent cases(49). In addition, women in our study also experienced violent behaviors by health care providers due to the protests to their discriminatory behaviors with the husband. A study in China on more than 1,000 health care providers showed that they had stigmatizing attitudes towards HIV patients like perceived social norms in the general population(50). Stigma from health care professionals is a worrying issue because it restricts access and use of services to couples(51). HIV / AIDS in addition to affecting community health leads to socioeconomic problems for individuals, families, communities and governments of many countries(52).

\section{Study limitations:}

The findings of the research are specific to Iranian women in serodiscordant relationships and cannot be generalized, although generalization is not a goal of qualitative research. There is a slight possibility that sociocultural issues are barriers for disclosure of violence and may hinder women to disclose the violence so that this could influence the responses of the participants. This study was conducted on a population of couples attending the Behavioral Disease Counseling Clinic, and other couples who did not attend the clinic were not interviewed, therefore, the findings are representative of only couples with this characteristic.

\section{Strengths:}


Notwithstanding the limitations of this study, there are several strengths to this study. The studies conducted about HIV/AIDS has mainly focused on the HIV positive individuals rather than HIV negative ones (53), but we conducted the study by qualitative method to obtain negative HIV women's viewpoints, who were in HIV serodiscordant relationships. The focus of the interviews was not only on the intimate partner and domestic violence, instead other forms of violence were also considered to provide insight in various aspects of violence.

\section{Recommendations:}

According to the findings of this study, it is recommended that HIV intervention programs should address gender-based violence among seroderodiscordant couples. It is argued that these findings can help policymakers in designing care plans and empowerment programs for HIV serodiscoedant couples. In addition, our findings indicate that there is a need to reform the rules of dealing with a spouse who has committed violence against women. Also, in order to better understanding of the problem of violence against women there is a need for more research. Suggestions for further research include investigating the perceptions of HIV positive men towards violence, to examine the cultural issues affecting the violence against women as well as the prevalence, causes and types of violence using quantitative methods in HIV serodiscordant couples.

\section{Conclusions}

This study provided an insight into different aspects of violence in Iranian women in serodiscordant HIV relationships. In summary, women experienced all types of violence. Traditional beliefs in the community and the lack of appropriate laws and services to deal with perpetrators of violence lead to continuing violence against women. Health care providers at HIV/ AIDS counseling centers should be able to address topics related to the violence for HIV negative women in serodiscordant relationships.

\section{Abbreviations}

UNAIDS: Joint United Nations Programme on HIV/AIDS

UNESCO: United Nations Educational, Scientific and Cultural Organization

\section{Declarations}

\section{Acknowledgements:}

This research is part of the first author's PhD thesis in reproductive health (Mona Larki), which was financially funded by Mashhad Medical Sciences University, Mashhad, Iran (Grant number: 970016). For the financial support of this study the research team would like to thank the Research Deputy of Mashhad University of Medical Sciences and the study participants who shared their experiences and time with us.

\section{Funding statement:}

Financially supported was by Mashhad University of Medical Sciences, Mashhad, Iran (Grant number: 970016).

\section{Author's contributions:}

LM contributed to study design, data collection, data analysis and initial drafting of the manuscript. BN contributed to the data analysis. LRR contributed to the study design, data analysis and supervision of the research process. All authors have critically reviewed and approved the final draft and are responsible for the content and similarity index of the manuscript.

\section{Availability of data and materials:}

On reasonable request, the datasets used and/or analyzed during the current study are available from the corresponding author.

Page $10 / 13$ 


\section{Ethics approval and consent to participate:}

Ethical clearance for this study was obtained from Local Research Ethics Committee of Mashhad University of Medical Sciences

(Code of Ethics. IR.MUMS.NURSE.REC.1397.022).

\section{Consent for publication:}

Not applicable.

\section{Conflict of interest:}

Authors declare no competing interests.

\section{References}

1. F A C T S HEET - G L O B A L A I D S U P D A T E 2019 [Internet]. 2019. Available from: https://www.unaids.org/sites/default/files/media_asset/UNAIDS_FactSheet_en.pdf.

2. Larki M, Roudsari RL. Home-Based Care, the Missing Link in Caring of Patients Living with HIV/AIDS and Their Family Members: A Narrative Review. International Journal of Community Based Nursing and Midwifery. 2020;8(3):190.

3. Larki M, Latifnejad Roudsari R. Home-Based Care, the Missing Link in Caring of Patients Living with HIV/AIDS and Their Family Members: A Narrative Review. International Journal of Community Based Nursing \& Midwifery. 2020;8(3):190-208.

4. Organization WH. Violence against women and HIV/AIDS: setting the research agenda: meeting report, Geneva, 23-25 October 2000. Geneva: World Health Organization; 2001.

5. Violence against women [Internet]. 2017 [cited 23 April 2019]. Available from: https://www.who.int/news-room/factsheets/detail/violence-against-women.

6. Qaisrani A, Liaquat S, Khokhar EN. Socio-economic and Cultural Factors of Violence against Women in Pakistan. 2016.

7. Patel RC, Leddy AM, Odoyo J, Anand K, Stanford-Moore G, Wakhungu I, et al. What motivates serodiscordant couples to prevent HIV transmission within their relationships: findings from a PrEP implementation study in Kenya. Culture, health \& sexuality. 2018;20(6):625-39.

8. Larki M. Living with Discordance: A Qualitative Description of the Challenges Faced by HIV Negative Married Women. International Journal of Community Based Nursing and Midwifery. 2020;8(2):103.

9. Mavhandu-Mudzusi AH. The Couple Interview as a Method of Collecting Data in Interpretative Phenomenological Analysis Studies. International Journal of Qualitative Methods. 2018;17(1):1609406917750994.

10. Ngilangwa DP, Ochako R, Mboya BA, Noronha RH, Mgomella GS. Prevalence and predictors of HIV sero-discordance among cohabiting couples tested in northern Tanzania. Pan African Medical Journal. 2015;22(1).

11. Baratedi WM, Thupayagale-Tsweneagae G, Gamba-Limando M. Experiences of the HIV serostatus disclosure in serodiscordant couples in three urban areas in Botswana. Life Science Journal. 2014;11(11).

12. Gitonga M BJ, Ndege S. Challenges and coping strategies among couples of mixed HIV status presenting at a large comprehensive care centre in Eldoret, Kenya. Journal of Biology, Agriculture and Healthcare. 2012;2:18-27.

13. Crankshaw TL, Mindry D, Munthree C, Letsoalo T, Maharaj P. Challenges with couples, serodiscordance and HIV disclosure: healthcare provider perspectives on delivering safer conception services for HIV-affected couples, South Africa. J Int AIDS Soc. 2014;17:18832.

14. Antelman G, Fawzi MCS, Kaaya S, Mbwambo J, Msamanga GI, Hunter DJ, et al. Predictors of HIV-1 serostatus disclosure: a prospective study among HIV-infected pregnant women in Dar es Salaam, Tanzania. AIDS (London, England). 2001;15(14):1865.

15. Bwambale FM, Ssali SN, Byaruhanga S, Kalyango JN, Karamagi CA. Voluntary HIV counselling and testing among men in rural western Uganda: implications for HIV prevention. BMC public health. 2008;8(1):263.

16. Mashaphu S, Wyatt G, Gomo E, Tomita A. Intimate partner violence among HIV-serodiscordant couples in Durban, South Africa. South African Medical Journal. 2018;108(11). 
17. Patel SN, Hennink MM, Hynes ME, Yount KM, Kosambiya JK, Wingood GM, et al. Pathways that affect wives' HIV risk among serodiscordant couples in India: results from the positive Jeevan Saathi Study. Qualitative health research. 2016;26(11):1531-42.

18. Gavey N. Just sex?: The cultural scaffolding of rape: Routledge; 2013.

19. White JW, Smith PH, Koss MP, Figueredo A. Intimate partner aggression-what have we learned? Comment on Archer (2000). 2000.

20. Testa M, Livingston JA, VanZile-Tamsen C. Advancing the study of violence against women using mixed methods: Integrating qualitative methods into a quantitative research program. Violence against women. 2011;17(2):236-50.

21. Murray LK, Haworth A, Semrau K, Singh M, Aldrovandi GM, Sinkala M, et al. Violence and abuse among HIV-infected women and their children in Zambia: a qualitative study. The Journal of nervous and mental disease. 2006;194(8):610.

22. Taherkhani S, Negarandeh R, Simbar M, Ahmadi F. Iranian women's experiences with intimate partner violence: a qualitative study. Health promotion perspectives. 2014;4(2):230.

23. Flinck A, Paavilainen E, Åstedt-Kurki P. Survival of intimate partner violence as experienced by women. Journal of clinical nursing. 2005;14(3):383-93.

24. Latifnejad Roudsari R. Qualitative description: A less sophisticated approach for junior qualitative researchers. Journal of Midwifery and Reproductive Health. 2019;7(4):1856-7.

25. Graneheim UH, Lundman B. Qualitative content analysis in nursing research: concepts, procedures and measures to achieve trustworthiness. Nurse education today. 2004;24(2):105-12.

26. Schlebusch L, Govender R. Elevated risk of suicidal ideation in HIV-positive persons. Depression research and treatment. $2015 ; 2015$.

27. Heise L, Ellsberg M, Gottmoeller M. A global overview of gender-based violence. International Journal of Gynecology \& Obstetrics. 2002;78:S5-S14.

28. Weiss E. Surviving domestic violence: Voices of women who broke free: Volcano Press; 2004.

29. Healey K. Violence in the family (Vol. 99). Balmain: The Spinney Press; 1998.

30. Tiwari A, Fong D, Chan K, Leung W, Parker B, Ho P. Identifying intimate partner violence: comparing the Chinese abuse assessment screen with the Chinese revised conflict tactics scales. BJOG: An International Journal of Obstetrics \& Gynaecology. 2007;114(9):1065-71.

31. Violence aganst women [Internet]. 2015 [cited 5 May 2019]. Available from: www.unesco.org/new/fileadmin/MULTIMEDIA/HQ/BSP/GENDER/PDF/Article_25_Nov_eng.pdf.

32. Van der Straten A, King R, Grinstead O, Vittinghoff E, Serufilira A, Allen S. Sexual coercion, physical violence, and HIV infection among women in steady relationships in Kigali, Rwanda. AIDS and Behavior. 1998;2(1):61-73.

33. Emusu D, Ivankova N, Jolly P, Kirby R, Foushee H, Wabwire-Mangen F, et al. Experience of sexual violence among women in HIV discordant unions after voluntary HIV counselling and testing: a qualitative critical incident study in Uganda. AIDS care. 2009;21(11):1363-70.

34. Ware NC, Wyatt MA, Haberer JE, Baeten JM, Kintu A, Psaros C, et al. What's love got to do with it? Explaining adherence to oral antiretroviral pre-exposure prophylaxis (PrEP) for HIV serodiscordant couples. Journal of acquired immune deficiency syndromes (1999). 2012;59(5).

35. McDonald K. 'The old-fashioned way': conception and sex in serodiscordant relationships after ART. Culture, health \& sexuality. 2011;13(10):1119-33.

36. Widom CS, Kuhns JB. Childhood victimization and subsequent risk for promiscuity, prostitution, and teenage pregnancy: a prospective study. American journal of public health. 1996;86(11):1607-12.

37. Were E, Curran K, Delany-Moretlwe S, Nakku-Joloba E, Mugo NR, Kiarie J, et al. A prospective study of frequency and correlates of intimate partner violence among African heterosexual HIV serodiscordant couples. AIDS (London, England). 2011;25(16):2009.

38. Smith M, Nunley B, Martin E. Intimate partner violence and the meaning of love. Issues in mental health nursing. 2013;34(6):395401.

39. Mitchell RE, Hodson CA. Coping with domestic violence: Social support and psychological health among battered women. American journal of community psychology. 1983;11(6):629-54. 
40. Kose S, Mandiracioglu A, Mermut G, Kaptan F, Ozbel Y. The social and health problems of people living with HIV/AIDS in Izmir, Turkey. The Eurasian journal of medicine. 2012;44(1):32.

41. Ramchandani SR, Mehta SH, Saple DG, Vaidya SB, Pandey VP, Vadrevu R, et al. Knowledge, attitudes, and practices of antiretroviral therapy among HIV-infected adults attending private and public clinics in India. AIDS Patient Care and STDs. 2007;21(2):129-42.

42. Rispel LC, Cloete A, Metcalf CA. 'We keep her status to ourselves': Experiences of stigma and discrimination among HIVdiscordant couples in South Africa, Tanzania and Ukraine. SAHARA-J: Journal of Social Aspects of HIV/AIDS. 2015;12(1):10-7.

43. Mitra A, Singh P. Human capital attainment and gender empowerment: the Kerala paradox. Social Science Quarterly. 2007;88(5):1227-42.

44. McCue ML. Domestic violence: A reference handbook: Abc-clio; 2008.

45. Taraphdar P, Guha RT, Haldar D, Chatterjee A, Dasgupta A, Saha B, et al. Socioeconomic consequences of HIV/AIDS in the family system. Nigerian medical journal: journal of the Nigeria Medical Association. 2011;52(4):250.

46. Fisher BS, Daigle LE, Cullen FT, Turner MG. Reporting sexual victimization to the police and others: Results from a national-level study of college women. Criminal justice and behavior. 2003;30(1):6-38.

47. Sullivan CM, Basta J, Tan C, Davidson II WS. After the crisis: A needs assessment of women leaving a domestic violence shelter. Violence and victims. 1992;7(3):267.

48. Klostermann K, Kelley M. Alcoholism and intimate partner violence: Effects on children's psychosocial adjustment. International Journal of Environmental Research and Public Health. 2009;6(12):3156-68.

49. Organization WH. Promoting gender equality to prevent violence against women. 2009.

50. Li L, Liang LJ, Lin C, Wu Z, Wen Y. Individual attitudes and perceived social norms: Reports on HIV/AIDS-related stigma among service providers in China. International Journal of Psychology. 2009;44(6):443-50.

51. Varas-Díaz N, Neilands TB. Development and validation of a culturally appropriate HIV/AIDS stigma scale for Puerto Rican health professionals in training. AIDS care. 2009;21(10):1259-70.

52. Trapero-Bertran M, Oliva-Moreno J. Economic impact of HIV/AIDS: a systematic review in five European countries. Health economics review. 2014;4(1):15.

53. Rivera-Rivera JN, Madera SLR, Varas-Díaz N, Pacheco RY. The role of social support on health-related practices of HIV-discordant heterosexual couples. Revista Puertorriqueña de Psicología. 2016;24(2):27-45 